\title{
Deinococcus deserti sp. nov., a gamma-radiation- tolerant bacterium isolated from the Sahara Desert
}

Correspondence

Arjan de Groot

nicolaas.degroot@cea.fr

\author{
Arjan de Groot, ${ }^{1}$ Virginie Chapon, ${ }^{1}$ Pascale Servant, ${ }^{2}$ Richard Christen, ${ }^{3}$ \\ Marion Fischer-Le Saux, ${ }^{4}$ Suzanne Sommer ${ }^{2}$ and Thierry Heulin ${ }^{1}$ \\ 'Laboratoire d'Écologie Microbienne de la Rhizosphère (LEMIR), UMR 6191 CNRS-CEA- \\ Université de la Méditerranée, DSV-DEVM, CEA Cadarache, F-13108 Saint-Paul-Lez-Durance, \\ France
} ${ }^{2}$ Institut de Génétique et Microbiologie, UMR 8621 CNRS-Université Paris-Sud, LRC CEA 42V,
Bâtiment 409, F-91405 Orsay cedex, France

${ }^{3}$ Biologie Virtuelle, UMR 6543 CNRS-Université de Nice, Parc Valrose, Centre de Biochimie, F-06108 Nice cedex 2, France

${ }^{4}$ UMR de Pathologie Végétale INRA-INH-Université d'Angers, BP 60057, 42 rue Georges Morel, F-49071 Beaucouzé cedex, France

Two gamma- and UV-radiation-tolerant, Gram-negative, rod-shaped bacterial strains, VCD115 ${ }^{\top}$ and VCD117, were isolated from a mixture of sand samples collected in the Sahara Desert in Morocco and Tunisia, after exposure of the sand to $15 \mathrm{kGy}$ gamma radiation. Phylogenetic analysis based on 16S rRNA gene sequences and DNA-DNA hybridizations showed that VCD115 ${ }^{\top}$ and VCD117 are members of a novel species belonging to the genus Deinococcus, with Deinococcus grandis as its closest relative. The DNA G $+C$ contents of VCD $115^{\top}$ and VCD117 are 59.8 and 60.6 mol\%, respectively. The major fatty acids (straight-chain $15: 1,16: 1,17: 1$ and $16: 0$ ), polar lipids (dominated by phosphoglycolipids and glycolipids) and quinone type (MK-8) support the affiliation to the genus Deinococcus. The strains did not grow on rich medium such as trypticase soy broth (TSB), but did grow as whitish colonies on tenfold-diluted TSB. The genotypic and phenotypic properties allowed differentiation of $\mathrm{VCD} 115^{\top}$ and VCD117 from recognized Deinococcus species. Strains VCD $115^{\top}$ and $\mathrm{VCD} 117$ are therefore identified as representing a novel species, for which the name Deinococcus deserti sp. nov. is proposed, with the type strain $\operatorname{VCD} 115^{\top}\left(=\mathrm{DSM} 17065^{\top}=\mathrm{LMG} 22923^{\top}\right)$.
Various bacterial species have the capacity to survive under conditions that are commonly considered as extreme, for example in environments experiencing high pressure or high salt concentrations. In our laboratory, we are studying bacteria that live in the upper sand layers of deserts, where they are exposed to cycles of high and low temperatures, and to cycles of desiccation and hydration. De- and rehydration may cause DNA damage in these bacteria, and in order to survive they probably possess efficient DNA-repair mechanisms. Ionizing radiation causes similar types of DNA

Published online ahead of print on 29 July 2005 as DOI 10.1099/ ijs.0.63717-0.

The GenBank/EMBL/DDBJ accession numbers for the 16S rRNA gene sequences of strains VCD $115^{\top}$ and VCD117 are AY876378 and AY876379, respectively.

Levels of $16 \mathrm{~S}$ rRNA gene sequence similarity and DNA-DNA relatedness between strains $\mathrm{VCD}^{1} 15^{\top}$ and $\mathrm{VCD} 117$ and rates of survival after gamma and UV irradiation are available as supplementary material in IJSEM Online. damage including double-strand breaks, which are the most deleterious to the organism (Mattimore \& Battista, 1996). Bacteria belonging to the genus Deinococcus, in particular the well-studied Deinococcus radiodurans, have the distinctive feature of being the most radiation-tolerant of vegetative cells. $D$. radiodurans can withstand doses of radiation a thousand times higher than a human can. It can survive doses of radiation that do not exist naturally on Earth. Therefore, it is likely that this radiation tolerance is related to the bacterial response to natural non-radioactive DNA-damaging conditions such as desiccation (Makarova et al., 2001). At the time of writing, eight recognized species belong to the genus Deinococcus (Ferreira et al., 1997; Rainey et al., 1997; Suresh et al., 2004). Three other species have been described very recently, 'Deinococcus frigens', 'Deinococcus saxicola' and 'Deinococcus marmoris' (Hirsch et al., 2004). Only $D$. radiodurans $\mathrm{R}_{1}{ }^{\mathrm{T}}$ has been studied extensively. Its genome has been sequenced (White et al., 1999), and analyses of the transcriptome (Liu et al., 2003; Tanaka et al., 2004) and proteome (Lipton et al., 2002) have been 
reported. However, there is not yet a precise explanation of how $D$. radiodurans repairs its damaged genome and thus why it is so radiotolerant (Edwards \& Battista, 2003; Narumi, 2003).

Two novel radiation-tolerant strains, $\mathrm{VCD} 115^{\mathrm{T}}$ and $\mathrm{VCD} 117$, were obtained after exposure of a mixture of desert sand samples, collected in the Sahara in Morocco and Tunisia, to a dose of $15 \mathrm{kGy}$ gamma radiation $\left(4 \cdot 2 \mathrm{kGy} \mathrm{h}^{-1},{ }^{60} \mathrm{Co}\right.$ source; CEA Cadarache), followed by isolation of surviving colony-forming bacteria on agar plates containing tenfolddiluted trypticase soy broth (TSB/10; $3 \mathrm{~g} \mathrm{l}^{-1}$ ) (Bacto; Becton Dickinson). The type strains Deinococcus grandis DSM $3963^{\mathrm{T}}$, Deinococcus indicus DSM $15307^{\mathrm{T}}$ and D. radiodurans DSM $20539^{\mathrm{T}}\left(=\mathrm{R}_{1}^{\mathrm{T}}\right)$ were obtained from the DSMZ. Single carbon-source assimilation tests were performed on RCV medium (Weaver et al., 1975), adjusted to $\mathrm{pH} 7 \cdot 5$, and supplemented with $0.5 \mathrm{~g}$ ammonium sulfate $1^{-1}, 0.05 \mathrm{~g}$ yeast extract $l^{-1}$ and $1 \%$ stock vitamin solution $\left[4 \mu \mathrm{g} \mathrm{ml}^{-1}\right.$ each of thiamine, riboflavin, pyridoxine, biotin, folic acid, nicotinic acid, pantothenic acid, L- $(+)$-ascorbic acid and cyanocobalamin]. Carbon sources were added at a final concentration of $1 \mathrm{~g} \mathrm{l}^{-1}$. Negative controls did not include the carbon source. Positive controls were TSB/10 and the RCV medium supplemented with trypton $\left(1 \cdot 7 \mathrm{~g} \mathrm{l}^{-1}\right)$ and yeast extract $\left(0 \cdot 3 \mathrm{~g} \mathrm{l}^{-1}\right)$. For all other tests, bacterial strains were cultivated at $30^{\circ} \mathrm{C}$ in TSB/10 or on agar plates containing the same medium. For Biolog GN2 plates, cells were resuspended in basal RCV medium (without yeast extract and vitamins). API $20 \mathrm{NE}$ strips (bioMérieux) were used according to the instructions of the manufacturer. Catalase activity was tested by putting a drop of $3 \%$ hydrogen peroxide solution on a colony. Bubble formation was used to indicate a positive reaction. Susceptibility to antibiotics was analysed on agar plates containing $2 \cdot 5,10,15$ and $25 \mu \mathrm{g}$ antibiotic $\mathrm{ml}^{-1}$. To determine the survival rate after exposure to gamma radiation, cultures were grown to an $\mathrm{OD}_{600}$ of about $0 \cdot 5$, irradiated at the desired dose, diluted serially and plated. Percentage survival was determined by comparing with unirradiated cultures. To determine the survival rate after exposure to UV radiation, serial dilutions of cultures $\left(\mathrm{OD}_{600}\right.$ of about $\left.0 \cdot 5\right)$ were spread on TSB/10 plates. Plates without their cover lids were immediately exposed to UV (UV-C, $254 \mathrm{~nm}$ ) for the desired dose and subsequently incubated at $30^{\circ} \mathrm{C}$. The UV dose was monitored by using a VLX-3W radiometer (Bioblock Scientific).

The rrs (16S rRNA) genes were amplified from colonies by PCR using the primers fD1 (5'-AGAGTTTGATCCTGGCTCAG-3', positions 8-27 on the Escherichia coli rrs gene) and S17 (5'-GTTACCTTGTTACGACTT-3', positions 14921509 on the E. coli rrs gene), and the entire PCR fragment was sequenced. This resulted in sequences of 1406 and 1407 bp for VCD $115^{\mathrm{T}}$ and VCD117, respectively. The new sequences were added and aligned by reference to a database of 120000 already aligned and analysed (neighbour-joining) 16S rRNA gene sequences. Subsequently, BLAST queries against the latest release of the Bacteria division of GenBank allowed us to verify that no closely related sequence was missing in the database. The 50 most closely related sequences were selected, Thermus aquaticus and Meiothermus ruber were added as outgroups, and alignments between these sequences were refined manually using SEAVIEW (Galtier et al., 1996). A first phylogenetic analysis using the neighbour-joining method and conserved domains of the sequences produced an initial tree. We then retained sequences only for type strains, which led to 12 sequences. Phylogenetic trees were constructed according to three different methods: neighbour joining (bioNJ) (Gascuel, 1997), maximum likelihood using the Global option and maximum parsimony. The latter two programs were from PHYLIP (Phylogeny Inference Package, version 3.573c, distributed by J. Felsenstein, Department of Genome Sciences, University of Washington, Seattle, USA). For the bioNJ analysis, a matrix distance was calculated according to the Kimura two-parameter correction. Bootstrap support was determined using 1000 replications, bioNJ and Kimura twoparameter corrections. The phylogenetic trees were drawn using NJPLOT (Perrière \& Gouy, 1996). Domains used to construct the final phylogenetic trees were positions 41-392 and 407-1406 of the 16S rRNA gene sequence of VCD115 ${ }^{\mathrm{T}}$, excluding domains difficult to align among all sequences.

Extraction of genomic DNA (Earl et al., 2002) and DNADNA hybridizations (Ezaki et al., 1989; Willems et al., 2001) were performed as described previously. For DNA-DNA hybridizations, four replicate wells were used and reciprocal hybridizations were carried out for all experiments. The DNA $\mathrm{G}+\mathrm{C}$ contents were determined by the thermal denaturation method (Marmur \& Doty, 1962) and were calculated by using the equation of Owen \& Lapage (1976). E. coli K-12 (DNA G + C content $50 \cdot 6 \mathrm{~mol} \%$ ) was used as a control. Extraction and analysis of fatty acids was performed by Dr R. M. Kroppenstedt at the DSMZ (Braunschweig, Germany) using the Sherlock Microbial Identification System (MIDI, Inc.). Polar lipid analyses were carried out by the Identification Service of the DSMZ and Dr B. J. Tindall, DSMZ. Quinone analysis was also performed by the DSMZ.

The 16S rRNA genes of the new strains $\mathrm{VCD} 115^{\mathrm{T}}$ and VCD117 showed a high level of similarity $(99 \cdot 7 \%$; see Supplementary Table S1 in IJSEM Online). According to phylogenetic analysis of the $16 \mathrm{~S}$ rRNA gene sequences, strains VCD $115^{\mathrm{T}}$ and VCD117 form a robust clade within the genus Deinococcus and this clade cannot be grouped consistently with any recognized species, suggesting that these two strains represent a novel species of Deinococcus (Fig. 1). Percentages of $16 \mathrm{~S}$ rRNA gene sequence similarity with other available sequences were calculated by parsing the result of BLAST analyses on the Bacteria division with the options 'no filter' and ' $\mathrm{W}=7$ ' (NCBI Standalone BLAST). Summing for similarities over High Scoring Pairs gave $90 \cdot 5$ and $90.7 \%$ similarity with $D$. grandis for strain VCD $115^{\mathrm{T}}$ and VCD117, respectively, with up to $95 \%$ similarity when 


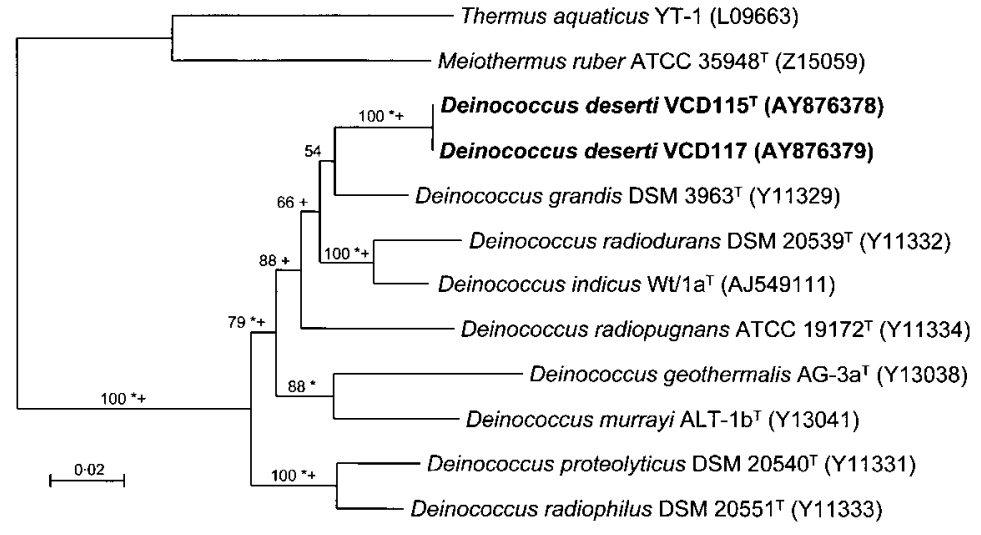

Fig. 1. Unrooted phylogenetic tree based on 16S rRNA gene sequence analysis, showing the relationship between the Deinococcus deserti strains and other Deinococcus species. The topology shown was obtained using the bioNJ algorithm with a Kimura two-parameter correction for the distances. Percentages of bootstrap support (1000 replications) are indicated as well as branches also retrieved by maximum parsimony $(+)$ and maximum likelihood $\left({ }^{*}, P<0.01\right)$; branches retrieved by all three methods should be considered as the only robust clades identified by this analysis. GenBank accession numbers are given in parentheses. excluding the $5^{\prime}$ part of the sequences. The $r r s$ genes of the recently isolated species ' $D$. frigens', ' $D$. marmoris' and ' $D$. saxicola', which were not included in the phylogenetic tree, are most similar to Deinococcus radiopugnans (Hirsch et al., 2004), which is distant from the VCD $115^{\mathrm{T}} / \mathrm{VCD} 117$ clade (Fig. 1). The 16S rRNA genes of $\mathrm{VCD} 115^{\mathrm{T}}$ and VCD117 possess the signature nucleotides $C, G, T, G, T, A, G, C$ and C at positions $657,749,757,1050,1208,1421,1429,1471$ and 1479 (E. coli 16S rRNA gene sequence numbering, GenBank accession number J01695), respectively, characteristic of the genus Deinococcus (Rainey et al., 1997). A signature nucleotide (C) was also reported at position 584 by Rainey et al. (1997), but the more recently described species Deinococcus geothermalis, Deinococcus murrayi and D. indicus, as well as strains $\mathrm{VCD} 115^{\mathrm{T}}$ and $\mathrm{VCD} 117$, have a $\mathrm{G}$ at this position.

Genomic DNA of strains VCD115 ${ }^{\mathrm{T}}$ and VCD117 was crosshybridized and hybridized with that of $D$. grandis, D. indicus and D. radiodurans. Between strains VCD $115^{\mathrm{T}}$ and VCD 117 , $78 \%$ reassociation was found ( 80 and $76 \%$ when DNA of strains $\mathrm{VCD} 115^{\mathrm{T}}$ and VCD117 was used as probe, respectively). By using the criterion of at least $70 \%$ hybridization for definition of a species (Wayne et al., 1987), we conclude that strains $\mathrm{VCD} 115^{\mathrm{T}}$ and VCD117 belong to the same species. A level of $<20 \%$ was found in all other DNA hybridization combinations (see Supplementary Table S1 in IJSEM Online). These results indicate that $\mathrm{VCD}_{11} 5^{\mathrm{T}}$ and VCD117 are members of a novel species, for which the name Deinococcus deserti sp. nov. is proposed. The DNA G+C contents were determined to be $59 \cdot 8$ and $60 \cdot 6 \pm 0 \cdot 5 \mathrm{~mol} \%$ for $\mathrm{VCD} 115^{\mathrm{T}}$ and VCD117, respectively. The DNA G $+\mathrm{C}$ content of other deinococcal species ranges from $59 \cdot 4$ to $70 \cdot 0 \mathrm{~mol} \%$ (Hirsch et al., 2004).

Cells of D. deserti VCD115 ${ }^{\mathrm{T}}$ and VCD117 are non-motile rods. Most of the cells were present as pairs, but chains of four cells were also regularly observed. Cells of $D$. grandis and D. indicus are also rod-shaped (Suresh et al., 2004), whereas those of all other members of the genus are spherical (Rainey et al., 1997; Hirsch et al., 2004). Colonies of VCD $115^{\mathrm{T}}$ and VCD117 were whitish on TSB/10 plates, unlike other Deinococcus species which were red-pigmented on this growth medium. However, when growth was obtained on RCV plates (for the carbon source assimilation tests, see below), the two $D$. deserti strains were faintly pinkpigmented. Colonies of D. radiodurans, D. indicus and $D$. grandis, in comparison with those of $D$. deserti, were strongly red-pigmented on these RCV plates. These results suggest that expression of genes involved in pigment formation may be regulated in $\mathrm{VCD}_{115^{\mathrm{T}}}$ and VCD117, whereas it is apparently constitutive in the other strains. Alternatively, unlike for the other Deinococcus strains, pigment biosynthesis in $\mathrm{VCD} 115^{\mathrm{T}}$ and VCD117 may require an exogenous compound as co-factor. As with cells of $D$. indicus and $D$. grandis, those of $D$. deserti stain Gram-negative, whereas those of other Deinococcus species stain Gram-positive (Suresh et al., 2004; Hirsch et al., 2004). D. deserti was routinely grown at $30^{\circ} \mathrm{C}$ in or on TSB/10. Growth was also observed at $37^{\circ} \mathrm{C}$ and slow growth at $23^{\circ} \mathrm{C}$, but not at $45^{\circ} \mathrm{C}$. Growth occurred between $\mathrm{pH} 6$ and $\mathrm{pH} 9$ with an optimum $\mathrm{pH}$ of about $7 \cdot 5$. Unlike the other Deinococcus type strains, the two $D$. deserti strains did not grow on plates containing the rich media LB, TGY (a trypton/glucose/yeast extract medium often used for growth of Deinococcus species; Brim et al., 2003) or undiluted TSB.

For the single carbon-source utilization assays, the results were almost identical for VCD115 ${ }^{\mathrm{T}}$ and VCD117 (Table 1). Good growth was observed on D-glucose, D-cellobiose, maltose, D-fructose, D-sorbitol, D-mannitol, starch and Casamino acids; moderate growth was observed on Lglutamate, acetate, D-galactose, sucrose, L-alanine, succinate and (though not for VCD117) L-histidine; no growth was observed on D-xylose, L-arabinose, myo-inositol, glycerol, D-ribose, lactose or L-tryptophan. On Biolog GN2 plates, utilization of additional carbon sources was observed, including D-psicose, succinic acid monomethyl ester, turanose, D-mannose and L-proline. The results of the carbon-utilization tests were very similar, but not identical, between $D$. deserti and the closely related $D$. grandis, but more differences were observed with the other species with rod-shaped cells, D. indicus (Table 1). On API 20 NE strips, which were incubated for up to 9 days, strain $\mathrm{VCD} 115^{\mathrm{T}}$ was 
Table 1. Phenotypic differences between $D$. deserti strains VCD115 ${ }^{\top}$ and VCD117, $D$. grandis and $D$. indicus

Strains: 1, D. deserti VCD115 ${ }^{\mathrm{T}}$; 2, D. deserti VCD117; 3, D. grandis DSM 3963 ${ }^{\mathrm{T}}$; , D. indicus DSM $15307^{\mathrm{T}}$. +, Positive; -, negative; $(+)$, weakly positive; NT, not tested. On RCV, all strains were (weakly) positive for utilization of D-cellobiose, maltose, sucrose, L-glutamate, L-alanine, succinate, starch and Casamino acids. On Biolog GN2 plates, D. deserti and D. grandis were (weakly) positive for D-glucose, sucrose, D-fructose, maltose, D-mannose, D-psicose, L-proline, dextrin and succinic acid monomethyl ester.

\begin{tabular}{|lcccc|}
\hline Characteristic & $\mathbf{1}$ & $\mathbf{2}$ & $\mathbf{3}$ & $\mathbf{4}$ \\
\hline DNA G+C content (mol\%) & 60 & 61 & 69 & 66 \\
Growth on rich media (TSB, LB, TGY) & - & - & + & + \\
Colony colour on TSB/10 & Whitish & Whitish & Red & Red \\
Carbon-source utilization on RCV medium & & & & \\
$\quad$ D-Glucose, D-fructose, D-sorbitol, D-mannitol & + & + & + & - \\
D-Xylose, L-arabinose, lactose & - & - & - & $(+)$ \\
Glycerol & - & - & + & + \\
L-Histidine & $(+)$ & - & $(+)$ & $(+)$ \\
Carbon-source utilization on Biolog GN2 & & & & \\
Turanose, D-galactose & + & + & - & NT \\
Lactulose, glycerol, methyl $\beta$-D-glucoside & - & - & - & NT \\
Formic acid & + & - & & \\
\end{tabular}

positive for protease and weakly positive for $\beta$-glucosidase and $\beta$-galactosidase. VCD117 was positive for protease and $\beta$-galactosidase and weakly positive for $\beta$-glucosidase. Protease production was confirmed by the observation of halo formation on plates containing $1 \%$ skimmed milk. VCD $115^{\mathrm{T}}$ and VCD 117 tolerated up to $25 \mu \mathrm{g}$ spectinomycin and nalidixic acid $\mathrm{ml}^{-1}$, and weak growth was observed at up to $10 \mu \mathrm{g}$ bacitracin $\mathrm{ml}^{-1}$. VCD $115^{\mathrm{T}}$ tolerated up to $0 \cdot 5 \%$ $\mathrm{NaCl}$ (added to TSB/10, which contains $0.05 \% \mathrm{NaCl}$ ), but only weak growth of VCD117 was observed in the presence of $0.5 \% \mathrm{NaCl}$.

The fatty acid composition was determined for VCD $115^{\mathrm{T}}$, VCD117 and the closest relative D. grandis, grown under the same conditions. Major fatty acids were straight chains $15: 1 \omega 6 c, 16: 1 \omega 7 c, 17: 1 \omega 8 c$ and $16: 0$ (Table 2), which are also predominant in most other Deinococcus species (Hirsch et al., 2004). Smaller amounts of iso-branched fatty acids were also found. Qualitative and quantitative differences between the strains, in particular between $D$. deserti and $D$. grandis, were also observed. For example, a 16:1 isobranched fatty acid was found in VCD $115^{\mathrm{T}}$ and VCD 117 but not detected in D. grandis. The polar lipid composition of VCD $115^{\mathrm{T}}$ was found to be dominated by three phosphoglycolipids (with one of them as the major polar lipid) and four glycolipids, which is typical for Deinococcus species (Thompson et al., 1980). Two phospholipids and one aminophospholipid were also detected. The major respiratory quinone of $\mathrm{VCD} 115^{\mathrm{T}}$ was menaquinone 8 (MK8).

Survival of cultures after exposure to increasing doses of gamma radiation was analysed for strains $\mathrm{VCD} 115^{\mathrm{T}}$ and VCD117, and compared with $D$. radiodurans $\mathrm{R}_{1}{ }^{\mathrm{T}}$ and $E$. coli
MC4100 (Supplementary Table S2). At the lowest dose tested $(2 \cdot 5 \mathrm{kGy})$, E. coli did not survive, whereas almost no loss in survival of strains $\mathrm{VCD}_{115^{\mathrm{T}}}$ and $\mathrm{R}_{1}^{\mathrm{T}}$ was observed. VCD117 appeared to be somewhat less tolerant than VCD $115^{\mathrm{T}}$; exposure of cultures to $2 \cdot 5,5$ and $7 \cdot 5 \mathrm{kGy}$ resulted in survival of 60,15 and $6 \%$, respectively, for VCD117, compared with 95, 94 and $23 \%$, respectively, for VCD $115^{\mathrm{T}}$. Survival of VCD $115^{\mathrm{T}}$ was comparable to that of $\mathrm{R}_{1}{ }^{\mathrm{T}}$. Strains VCD $115^{\mathrm{T}}$ and VCD117 also appeared to be extremely tolerant to UV radiation, with $\mathrm{VCD} 115^{\mathrm{T}}$ being much more tolerant than VCD117 and D. radiodurans $\mathrm{R}_{1}{ }^{\mathrm{T}}$ (Supplementary Table S2). Whereas E. coli did not survive the lowest dose tested $\left(250 \mathrm{~J} \mathrm{~m}^{-2}\right), 73$ and $11 \%$ survival was observed at this dose for $\mathrm{VCD} 115^{\mathrm{T}}$ and $\mathrm{VCD} 117$, respectively, and more than $1 \%$ of the $\mathrm{VCD} 115^{\mathrm{T}}$ cells survived after exposure to UV doses as high as $750 \mathrm{~J} \mathrm{~m}^{-2}$.

To summarize, the phenotypic characteristics of strains $\mathrm{VCD} 115^{\mathrm{T}}$ and VCD117 are very similar, supporting the conclusion from the phylogenetic analysis and DNA-DNA hybridizations that they belong to the same species. Nevertheless, $\mathrm{VCD} 115^{\mathrm{T}}$ is more tolerant to gamma and UV radiation than is VCD117. It is highly likely that tolerance to radiation depends on numerous gene products and other factors such as growth conditions. Some of the genes that contribute to radiotolerance may be less active or even inactivated or absent in VCD117 compared with VCD $115^{\mathrm{T}}$. Gene inactivation may occur by an insertion sequence (IS) element, as exemplified by a DNA damagesensitive $D$. radiodurans strain that contained an IS in the uvrA gene (Narumi et al., 1997). After D. grandis and D. indicus, $\operatorname{VCD} 115^{\mathrm{T}}$ and $\mathrm{VCD} 117$ belong to a third Deinococcus species with rod-shaped cells. Unlike other 
Table 2. Fatty acid composition of strains $\mathrm{VCD} 115^{\top}$, VCD117 and D. grandis DSM $3963^{\top}$

Values are percentages of the total fatty acid content. The three major fatty acids for each strain are shown in bold. -, Not detected.

\begin{tabular}{|c|c|c|c|}
\hline Fatty acid & $\mathrm{VCD} 115^{\mathrm{T}}$ & VCD117 & D. grandis \\
\hline $10: 0$ iso & $0 \cdot 24$ & - & - \\
\hline $12: 0$ iso & $0 \cdot 24$ & $0 \cdot 75$ & - \\
\hline $13: 0$ iso & - & - & $0 \cdot 89$ \\
\hline $13: 0$ & - & - & $0 \cdot 66$ \\
\hline $14: 0$ iso & - & $0 \cdot 59$ & - \\
\hline $14: 1 \omega 5 c$ & - & - & $0 \cdot 35$ \\
\hline $14: 0$ & - & $0 \cdot 71$ & $0 \cdot 82$ \\
\hline $15: 1$ iso $^{\star} / 13: 03-\mathrm{OH}$ & - & - & $0 \cdot 95$ \\
\hline $15: 0$ iso & $0 \cdot 33$ & $0 \cdot 67$ & $9 \cdot 88$ \\
\hline $15: 0$ anteiso & - & - & $0 \cdot 28$ \\
\hline $15: 1 \omega 8 c$ & $1 \cdot 6$ & $1 \cdot 25$ & $1 \cdot 34$ \\
\hline $15: 1 \omega 6 c$ & $7 \cdot 77$ & $3 \cdot 60$ & $17 \cdot 24$ \\
\hline $15: 0$ & $3 \cdot 25$ & $6 \cdot 70$ & $9 \cdot 26$ \\
\hline $16: 1$ iso $^{*}$ & $5 \cdot 16$ & $4 \cdot 33$ & - \\
\hline $16: 0$ iso & $5 \cdot 67$ & $6 \cdot 16$ & $0 \cdot 97$ \\
\hline $16: 1 \omega 9 c$ & $2 \cdot 72$ & $3 \cdot 56$ & $0 \cdot 75$ \\
\hline $16: 1 \omega 7 c$ & $29 \cdot 39$ & $35 \cdot 23$ & $19 \cdot 23$ \\
\hline $16: 1 \omega 5 c$ & $0 \cdot 52$ & - & $1 \cdot 97$ \\
\hline $16: 0$ & $7 \cdot 07$ & $12 \cdot 11$ & $9 \cdot 90$ \\
\hline $17: 1 \omega 9 c$ iso & $5 \cdot 39$ & $4 \cdot 85$ & $1 \cdot 01$ \\
\hline $17: 1$ anteiso ${ }^{\star} / 17: 1$ iso $^{*}$ & - & - & $1 \cdot 71$ \\
\hline $17: 1$ anteiso $^{*}$ & - & $3 \cdot 31$ & - \\
\hline $17: 1 \omega 9 c$ anteiso & $0 \cdot 23$ & - & - \\
\hline $17: 0$ iso & $1 \cdot 65$ & $1 \cdot 72$ & $8 \cdot 13$ \\
\hline $17: 1 \omega 8 c$ & $14 \cdot 14$ & $6 \cdot 91$ & $2 \cdot 95$ \\
\hline $17: 1 \omega 6 c$ & $4 \cdot 88$ & $2 \cdot 07$ & $4 \cdot 10$ \\
\hline $17: 0$ & $4 \cdot 08$ & $2 \cdot 46$ & $7 \cdot 59$ \\
\hline $17: 0$ 10-methyl & $0 \cdot 71$ & - & - \\
\hline $18: 1$ iso $^{\star}$ & $2 \cdot 87$ & $1 \cdot 26$ & - \\
\hline $18: 0$ iso & $0 \cdot 86$ & $0 \cdot 63$ & - \\
\hline $18: 1 \omega 9 c$ & $0 \cdot 57$ & $0 \cdot 46$ & - \\
\hline $18: 1 \omega 7 c$ & $0 \cdot 65$ & $0 \cdot 67$ & - \\
\hline
\end{tabular}

${ }^{\star}$ Double bond position and/or configuration uncertain.

Deinococcus species, $\mathrm{VCD} 115^{\mathrm{T}}$ and VCD117 do not grow on rich media and are not (on TSB/10) or are only faintly (on RCV) pink-pigmented. Carbon-source utilization and fatty acid composition of VCD $115^{\mathrm{T}}$ and VCD117 allow further differentiation from $D$. grandis and D. indicus. Phylogenetic, chemotaxonomic and physiological differences with the other Deinococcus species support the description of a novel species for strains VCD $115^{\mathrm{T}}$ and VCD117.

\section{Description of Deinococcus deserti sp. nov.}

Deinococcus deserti (des.er'ti. L. gen. n. deserti of a desert).

Cells are non-motile and rod-shaped. Cell division occurs by constriction. Gram-negative. Whitish, smooth, circular, uniform-edged colonies of $0 \cdot 5-1 \mathrm{~mm}$ after $72 \mathrm{~h}$ at $30^{\circ} \mathrm{C}$ on TSB/10 plates. Faintly pink-pigmented on RCV plates. Growth is observed up to $0.5 \% \mathrm{NaCl}$. Generation time of the type strain in TSB/10 is $3 \mathrm{~h}$. No growth is observed on plates containing rich media. Carbon source utilization is

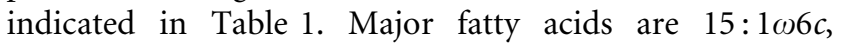
$16: 1 \omega 7 c, 17: 1 \omega 8 c$ and 16:0. Phosphoglycolipids and glycolipids are the major polar lipids. Major respiratory quinone is MK8. Strictly aerobic, and positive for protease and catalase. Resistant to spectinomycin and nalidixic acid, but sensitive to ampicillin, carbenicillin, tetracycline, kanamycin, gentamicin, streptomycin, chloramphenicol and rifampicin. Tolerates high doses of gamma and UV radiation. DNA G $+\mathrm{C}$ content is $59 \cdot 8 \mathrm{~mol} \%$ for the type strain.

The type strain, $\operatorname{VCD} 115^{\mathrm{T}}\left(=\mathrm{DSM} 17065^{\mathrm{T}}=\mathrm{LMG} 22923^{\mathrm{T}}\right)$, was isolated from gamma-irradiated mixed sand samples from the Sahara Desert in Morocco and Tunisia. Strain VCD117 is a reference strain.

\section{Acknowledgements}

We thank Jean Euzéby and Milton da Costa for taxonomic advice, Mohamed Barakat for help with some experiments, José Vicente for gamma irradiation and Edmond Jolivet, Odile Berge and Wafa Achouak for critical reading of the manuscript.

\section{References}

Brim, H., Venkateswaran, A., Kostandarithes, H. M., Fredrickson, J. K. \& Daly, M. J. (2003). Engineering Deinococcus geothermalis for bioremediation of high-temperature radioactive waste environments. Appl Environ Microbiol 69, 4575-4582.

Earl, A. M., Mohundro, M. M., Mian, I. S. \& Battista, J. R. (2002). The IrrE protein of Deinococcus radiodurans $\mathrm{R} 1$ is a novel regulator of recA expression. J Bacteriol 184, 6216-6224.

Edwards, J. S. \& Battista, J. R. (2003). Using DNA microarray data to understand the ionizing radiation resistance of Deinococcus radiodurans. Trends Biotechnol 21, 381-382.

Ezaki, T., Hashimoto, Y. \& Habuchi, E. (1989). Fluorometric deoxyribonucleic acid-deoxyribonucleic acid hybridization in microdilution wells as an alternative to membrane filter hybridization in which radioisotopes are used to determine genetic relatedness among bacterial strains. Int J Syst Bacteriol 39, 224-229.

Ferreira, A. C., Nobre, M. F., Rainey, F. A., Silva, M. T., Wait, R., Burghardt, J., Chung, A. P. \& da Costa, M. S. (1997). Deinococcus geothermalis sp. nov. and Deinococcus murrayi sp. nov., two extremely radiation-resistant and slightly thermophilic species from hot springs. Int J Syst Bacteriol 47, 939-947.

Galtier, N., Gouy, M. \& Gautier, C. (1996). SEAVIEW and PHYLO_WIN, two graphic tools for sequence alignment and molecular phylogeny. Comput Appl Biosci 12, 543-548.

Gascuel, O. (1997). BIONJ, an improved version of the NJ algorithm based on a simple method of sequence data. Mol Biol Evol 14, 685-695.

Hirsch, P., Gallikowski, C. A., Siebert, J., Peissl, K., Kroppenstedt, R., Schumann, P., Stackebrandt, E. \& Anderson, R. (2004). Deinococcus frigens sp. nov., Deinococcus saxicola sp. nov., and Deinococcus marmoris sp. nov., low temperature and draught-tolerating, 
UV-resistant bacteria from continental Antarctica. Syst Appl Microbiol 27, 636-645.

Lipton, M. S., Paša-Tolič, L., Anderson, G. A. \& 18 other authors (2002). Global analysis of the Deinococcus radiodurans proteome by using accurate mass tags. Proc Natl Acad Sci U S A 99, 11049-11054.

Liu, Y., Zhou, J., Omelchenko, M. V. \& 12 other authors (2003). Transcriptome dynamics of Deinococcus radiodurans recovering from ionizing radiation. Proc Natl Acad Sci U S A 100, 4191-4196.

Makarova, K. S., Aravind, L., Wolf, Y. I., Tatusov, R. L., Minton, K. W., Koonin, E. V. \& Daly, M. J. (2001). Genome of the extremely radiation-resistant bacterium Deinococcus radiodurans viewed from the perspective of comparative genomics. Microbiol Mol Biol Rev 65, 44-79.

Marmur, J. \& Doty, P. (1962). Determination of the base composition of deoxyribonucleic acid from its thermal denaturation temperature. J Mol Biol 5, 109-118.

Mattimore, V. \& Battista, J. R. (1996). Radioresistance of Deinococcus radiodurans: functions necessary to survive ionizing radiation are also necessary to survive prolonged desiccation. J Bacteriol 178, 633-637.

Narumi, I. (2003). Unlocking radiation resistance mechanisms: still a long way to go. Trends Microbiol 11, 422-425.

Narumi, I., Cherdchu, K., Kitayama, S. \& Watanabe, H. (1997). The Deinococcus radiodurans uvrA gene: identification of mutation sites in two mitomycin-sensitive strains and the first discovery of insertion sequence element from deinobacteria. Gene 198, 115-126.

Owen, R. J. \& Lapage, S. P. (1976). The thermal denaturation of partly purified bacterial deoxyribonucleic acid and its taxonomic implications. J Appl Bacteriol 41, 335-340.
Perrière, G. \& Gouy, M. (1996). WWW-QUERY: an on-line retrieval system for biological sequence banks. Biochimie 78, 364-369.

Rainey, F. A., Nobre, M. F., Schumann, P., Stackebrandt, E. \& da Costa, M. S. (1997). Phylogenetic diversity of the deinococci as determined by $16 \mathrm{~S}$ ribosomal DNA sequence comparison. Int J Syst Bacteriol 47, 510-514.

Suresh, K., Reddy, G. S., Sengupta, S. \& Shivaji, S. (2004). Deinococcus indicus sp. nov., an arsenic-resistant bacterium from an aquifer in West Bengal, India. Int J Syst Evol Microbiol 54, 457-461.

Tanaka, M., Earl, A. M., Howell, H. A., Park, M. J., Eisen, J. A., Peterson, S. N. \& Battista, J. R. (2004). Analysis of Deinococcus radiodurans's transcriptional response to ionizing radiation and desiccation reveals novel proteins that contribute to extreme radioresistance. Genetics 168, 21-33.

Thompson, B. G., Anderson, R. \& Murray, R. G. (1980). Unusual polar lipids of Micrococcus radiodurans strain Sark. Can J Microbiol 26, 1408-1411.

Wayne, L. G., Brenner, D. G., Coldwell, R. R. \& 8 other authors (1987). Report of the ad hoc committee on approaches to bacterial systematics. Int J Syst Bacteriol 37, 463-464.

Weaver, P. F., Wall, J. D. \& Gest, H. (1975). Characterization of Rhodopseudomonas capsulata. Arch Microbiol 105, 207-216.

White, O., Eisen, J. A., Heidelberg, J. F. \& 29 other authors (1999). Genome sequence of the radioresistant bacterium Deinococcus radiodurans $\mathrm{R} 1$. Science 286, 1571-1577.

Willems, A., Doignon-Bourcier, F., Goris, J., Coopman, R., de Lajudie, P., De Vos, P. \& Gillis, M. (2001). DNA-DNA hybridization study of Bradyrhizobium strains. Int $J$ Syst Evol Microbiol 51, 1315-1322. 